\title{
Strategic view of an assets health index for making long-term decisions in different industries
}

\author{
A. De la Fuente, A. Guillén, A. Crespo, A. Sola, J. Gómez \& P. Moreu \\ Department of Industrial Management, School of Engineering, University of Seville, Seville, Spain \\ V. Gonzalez-Prida \\ Department of Industrial Management, School of Engineering, University of Seville, Seville, Spain \\ UNED, Madrid, Spain
}

\begin{abstract}
An Asset Health Index (AHI) is a tool that processes data about asset's condition. That index is intended to explore if alterations can be generated in the health of the asset along its life cycle. These data can be obtained during the asset's operation, but they can also come from other information sources such as geographical information systems, supplier's reliability records, relevant external agent's records, etc. The tool (AHI) provides an objective point of view in order to justify, for instance, the extension of an asset useful life, or in order to identify which assets from a fleet are candidates for an early replacement as a consequence of a premature aging. This paper develops a model applicable to different classes of equipment and industrial sectors. A review of the main cases where the asset health index has been applied is included. Likewise, advantages and disadvantages in the application of this kind of tools are revealed, providing a guide for a research line related to the general application of this tool.
\end{abstract}

\section{INTRODUCTION}

Nowadays, network operators are facing many challenges in their assets management. There is an increasing trend for stakeholders (safety, reliability, environment, and financial impact) while assets are aging, increasing the risk of failure. The need to estimate the expected time to failure becomes more relevant every day, and planning for an optimal replacement or maintenance program to renew assets becomes even more essential. By having a large amount of assets, the maintenance manager's challenge is to decide which assets require more attention and what actions should be taken. The complexity of this decision increases because each asset class has different failure modes, and each failure has different consequences in the asset network (Vermeer et al. 2015).

The objective of this contribution is to highlight the most relevant recent studies related to the asset health index. The concept of asset health index (AHI) and its application appear throughout this document. The different models will be divided into three parts. The first part deals with data gathering and their treatment, the second part corresponds to the index composition, and the third part is the output of results and recommendations related to the index value. As a final part of the contribution, limitations of the models and the future scope of asset health index are discussed.

\section{CONCEPT OF AN ASSETS HEALTH INDEX}

An Asset Health Index (AHI) is an asset score, which is designed, in some way, to reflect or characterize the asset's condition and thus, its performance in terms of fulfilling the role established by the organization.

AHI represent a practical method to quantify the general health of a complex asset. Most of these assets are composed of multiple subsystems, and each subsystem can be characterized by multiple modes of degradation and failure. In some cases, it may be considered that an asset has reached the end of its useful life, when several subsystems have reached a state of deterioration that prevents the continuity of service required by the business (Hjartarson \& Otal 2006). Therefore, the health index, based on the results of operational observations, field inspections and laboratory tests, produces a single objective and quantitative indicator. It may be used as a tool to manage assets, to identify capital investment needs and maintenance programs (Naderian et al. 2008). In addition to condition and operation factors, the health index requires also to contain static factors linked to its location. That means, when environmental conditions are changed independently of the asset itself or the lack of any other change over time (Scatiggio \& Pompili 2013). 
The critical objectives in the formulation of a complex Health Index are as follows (Hjartarson \& Otal 2006):

- The index should be indicative of the asset suitability for a continued service and representative of the overall asset health.

- The index should contain objective and verifiable measures of asset condition, as opposed to subjective observations.

- The index should be understandable and readily interpreted.

\section{MODELS}

Next, four different models from the literature (proposed for the calculation of an asset health index) will be studied. In general terms, they all have inputs to the model that can be data related to condition, equipment operation, the availability of spare parts used in the maintenance and, in some cases, information from the geographic location.

For the algorithms used in the index calculation, it will be seen how in the different models, all the information sources are integrated by weighting factors and depending on the maturity level of the model implemented in each sector. Likewise, the output study for each model and their recommendations is shown.

The following scheme (Figure 1) represents the concept of an AHI. It tries to compile the different inputs to the model from the literature consulted, and the different outputs for making long-term decisions (Azmi et al. 2017). It is important to highlight that this paper is focused on making long-term decisions. In any case, there are also AHI models that are used as tools in the field of Prognostics and Health Management (P.H.M.) (Ludovic et al. 2011) (Abichou et al. 2012; Abichou et al. 2015).

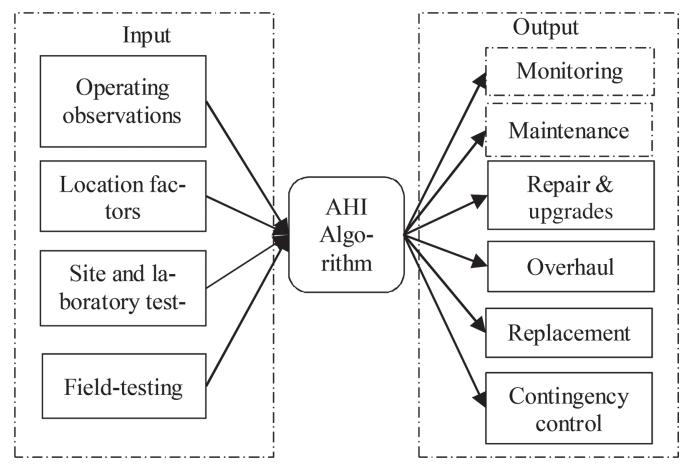

Figure 1. Concept of the health index within an asset management framework.

\subsection{Asset health index calculation model by Kinetrics}

The model developed by Kinetrics, Canada, proposes the overall assessment of transformers condition. The inputs to the model are data from different variables related to the operation and condition of the equipment throughout its useful life. The calculations for each variable, as well as detailed assessment are used to normalize the values, weighting them with corresponding weights and building a personalized asset health index.

\subsubsection{Inputs}

The inputs of the model, are the historical data of the variables of operation (load, number of operations, etc.), the results of oil samples labs tests (Oil quality, content in dissolved gases, acidity, etc.) and on-site tests carried out by technicians, such as insulation tests, thermography, corrosion status, etc.

\subsubsection{Index calculation methodology}

The methodology proposed for the index calculation is based on the normalization of each variable into a value between 0 and 4, together with a variable weight for the final composition in a single indicator.

As an example of standardization for the results obtained at a laboratory test, the following chart (Table 1) shows the link between concentration of dissolved gases in transformer oil and aging. In the table, concentrations of different dissolved gases are weighted, according to their relationship with the aging of the asset. Therefore, gases with greater weight are those that appear when the asset has reached a certain level of aging (Naderian et al. 2008).

Equation 1 below, calculated from the results of gases dissolved in oil, refers to the variable value which is one of the inputs to the AHI.

$$
\text { LTCOil Quality }=\frac{\sum_{i=1}^{4} S_{i} x W_{i}}{\sum_{I=1}^{4} W i}
$$

For the variables, the author proposes a weight between 1 and 10 . Values close to 1 are assigned

Table 1. Concentration in ppm of gas dissolved in oil.

\begin{tabular}{llcccc}
\hline & \multicolumn{5}{c}{ Gas in oil concentration in tap changer } \\
\cline { 2 - 5 } Gas & ppm & ppm & ppm & ppm & $\mathrm{W}_{\mathrm{i}}$ \\
\hline $\mathrm{CH}_{4}$ & $<50$ & $50-150$ & $150-250$ & $\geq 250$ & 3 \\
$\mathrm{C}_{2} \mathrm{H}_{6}$ & $<30$ & $30-50$ & $50-100$ & $\geq 100$ & 3 \\
$\mathrm{C}_{2} \mathrm{H}_{4}$ & $<100$ & $100-200$ & $200-500$ & $\geq 500$ & 3 \\
$\mathrm{C}_{2} \mathrm{H}_{4}$ & $<10$ & $10-20$ & $20-25$ & $\geq 25$ & 3 \\
\hline Score $\left(\mathrm{S}_{\mathrm{i}}\right)$ & 1 & 2 & 3 & 4 & \\
\hline
\end{tabular}


to variables whose relationship with the aging of the equipment is very small or null. On the other hand, for variables that take higher values (higher than 5 points), they are condition variables that more accurately reflect the aging of the equipment. The operating variables, such as the load factor of transformers and the power factor, are also related to the equipment aging speed, because they are good indicators showing when the equipment operates outside the design conditions.

\subsubsection{Model outputs}

For the model output, the author proposes a composition of all normalized variables in a single indicator ranging between 0 and 100 . The value of 100 corresponds to a value of new equipment and the value of zero refers to a piece of equipment that has reached the end of its useful life, requiring to be replaced because it is already out of service. The following equation 2 is proposed by the author for calculating the health index (Naderian et al. 2008).

$$
H I=60 \% \frac{\sum_{j=1}^{17} K_{j} H I F_{j}}{\sum_{j=1}^{17} 4 K_{j}}+40 \% \frac{\sum_{j=18}^{20} K_{j} H I F_{j}}{\sum_{j=18}^{20} 4 K_{j}}
$$

The index value is related to a failure probability of the equipment, being divided into different ranges with their respective interpretations and recommendations. For the different index output ranges, some recommendations and measures are proposed in order to be taken into account for decision making in maintenance management. The following Figure 2 shows the relationship between the health index and the probability of failure (Naderian et al. 2009).

\subsection{Asset health index calculation model by DNV GL}

This model developed by DNV GL, Arnhem, the Netherlands, proposes a methodology for the

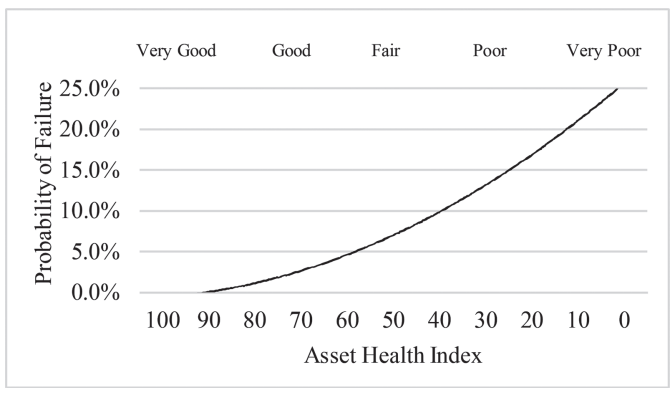

Figure 2. Asset health index ranges and the relationship with the probability of failure. calculation of a health index, calculated from the maximum admissible failure rates for the business, together with the asset criticality, in order to obtain an index to prioritize maintenance, overhaul and substitutions of parts. It uses as input variables the estimated useful life of the equipment, the current age and condition variables (load, on-site condition analysis, maintenance number, etc.). The output of this model is the remaining useful life of the equipment in years (Vermeer et al. 2015).

\subsubsection{Inputs}

The model uses the useful life of the equipment as static data; this allows making a first estimation that will be corrected later with the information of the asset's condition and, at the same time, with the failure modes that appear throughout the asset life cycle.

\subsubsection{Index calculation methodology}

The methodology proposed by the author, is separated into three large blocks, depending on the type of data entry. The blocks are called as degradation function, static function and condition function. The model output is the relationship between the different functions for determining the health index, which is in this case the equipment remaining life.

The model application requires a previous estimation of the asset average age based on historical data. This average life becomes a technical life average that is later corrected with the specific condition data of the asset. In a simple way, the model increases or decreases the end of the asset technical life, depending on the real asset condition at the moment of its analysis, Figure 3, (Vermeer et al. 2015).

\begin{tabular}{|c|c|c|}
\hline $\begin{array}{l}\text { Date of manu- } \\
\text { facturing }\end{array}$ & Current date & $\begin{array}{l}\text { End of technical } \\
\text { life (EoTL) }\end{array}$ \\
\hline Past life & \multicolumn{2}{|c|}{$\begin{array}{l}\text { Estimated remaining life under normal op- } \\
\text { erating conditions (years) }\end{array}$} \\
\hline \multicolumn{3}{|c|}{ Condition Assessment output } \\
\hline Criteria & $\begin{array}{l}\text { Subtract Years to } \\
\text { EoTL }\end{array}$ & $\begin{array}{l}\text { Add years to } \\
\text { EoTL }\end{array}$ \\
\hline Design / Quality & Poor & Good \\
\hline Spare part availability & Poor & Good \\
\hline Past maintenance & Too little & Sufficient \\
\hline $\begin{array}{l}\text { Future maintenance } \\
\text { costs }\end{array}$ & Increase & Decrease \\
\hline Wear from past loading & Much & Little \\
\hline Future loading / use & Increase & Decrease \\
\hline Inflicted damage & Yes & \\
\hline
\end{tabular}

Figure 3. Estimated remaining life corrected with the specific condition data of the asset. 


\subsubsection{Model outputs}

Once calculated all proposed methodological functions, they are combined in order to provide the result of the asset remaining life. In order to make the calculation, first, the static function is calculated with condition function in series, while the degradation function is calculated in parallel with the others. Like the previous model, the index output provides an approximated value of the asset health status, which is in this case the equipment remaining life. In Figure 4, the combination between the different functions is observed for the calculation of the asset health index proposed by the author.

\subsection{Asset health index calculation model by TERNA}

This model developed by Terna Rete, Italy, proposes the calculation of the equipment health index based on static and dynamic parameters. Static parameters are associated with the location where the equipment is located, which are invariable in time and independent of the asset, for example, the recurrence of catastrophic phenomena, the probability of electrical storm, etc. Dynamic parameters are associated to the equipment and can be measured in situ by functional and visual tests, as well as in laboratory tests by analysis of oil samples, lubricants, etc.

The output of the model is an index between 0 and 0.5 which refer to the state as new and critical respectively. That is intended to justify technically and economically, making decisions for the investment of capital in replacement of equipment (Scatiggio et al. 2016; Scatiggio \& Pompili 2013).

\subsubsection{Inputs}

The model author proposes static and dynamic variables for the model's inputs. Static variables do not depend on the asset itself but depend on the location (lightning frequency, catastrophic events, etc.). The dynamic variables proposed depend on the asset, and their value changes with the asset ages. Therefore, by capturing the change over time and comparing the maximum and minimum

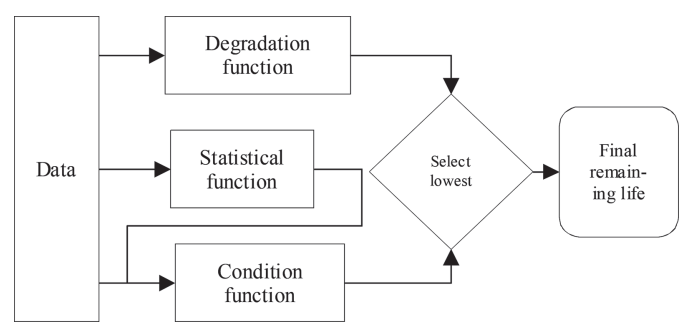

Figure 4. Schematic of how the functions are combined to give a health index. admissible for each kind of equipment, the condition status can be estimated at each moment of the asset life. The following condition parameters are those that are taken into account as inputs to the model (Pompili \& Scatiggio 2015), each parameter is known as Health Index (HI).

- HI dielectric: parameters related to dielectric and thermal condition, as it may be obtained from dissolved gas analysis. These parameters are able to provide information on electrical (partial discharges, low energy discharges, arcing) and thermal problems (hot spots, overloads);

- HI thermal: parameters related to pure thermal condition of the insulating paper, as they may be obtained from the $\mathrm{CO}_{2}, \mathrm{CO}$ and further periodical determinations;

- HI mechanical: parameters related to mechanical condition of the transformer, as they may be obtained from on-site electrical tests (inductance measurements, Sweep Frequency Response Analysis or SFRA, Frequency Domain Spectroscopy or PDC/FDS);

- HI oil: parameters related to insulating oil condition, as they may be obtained by water content, acidity, 50-60 Hz Breakdown Voltage (BDV) and Dielectric Dissipation Factor (DDF) determinations.

\subsubsection{Index calculation methodology}

Due to the fact that different condition factors are very different from each other, they must first be standardized with their corresponding weights. In order to transform the value into a non-dimensional number, international guidelines and regulations (IEC, IEEE, CIGRE, etc.) are used.

Once the parameters have been standardized, from the following equation 3 , the $\mathrm{HI}$ is calculated:

$$
H I=\frac{H I_{\text {dielectric }}+H I_{\text {thermal }}+H I_{\text {mechanical }}+H I_{\text {oil }}}{H I_{M A X}}
$$

where $\mathrm{HI}_{\mathrm{MAX}}$ is a prefixed number and, as a consequence, the $\mathrm{HI}$ of each asset may be expressed per units (p.u.).

\subsubsection{Model outputs}

The model output is a HI value between 0 and 0.5 . Higher and lower HI values are associated, respectively, to lower or higher levels of asset reliability.

In dependence on their HI, assets are classified in four classes. In Table 2, assets classified in "very good" and "good" condition may be managed following the common and standard maintenance practices, assets classified as "fair" or "doubtful" need an increase of analysis frequency or a deeper investigation (Scatiggio et al. 2016). 
Table 2. Health Index (HI) evaluation.

\begin{tabular}{ll}
\hline Health Index $(\mathrm{HI})$ & Condition \\
\hline $0-0,10$ & Very Good \\
$0,10-0,20$ & Good \\
$0,20-0,30$ & Fair \\
$>0,30$ & Doubtful \\
\hline
\end{tabular}

The models that will be introduced in the paper are relevant, among other things, because:

- Asset managers need models to study options that maximise the value of an asset as it approaches the end of its useful life. Options may include (for example) changing the operating regime, partial asset replacement/refurbishment to extend useful life, or an indefinite ongoing 'patch-and-continue' programme, perhaps involving suppliers to provide necessary parts or services.

- Predicted performance supported by knowledge and asset information is available in many companies - normally based on good understanding of how assets degrade - but not incorporated in formal processes for capital investment. These models contribute to the decision process that seeks the optimal life cycle value.

\section{CHALLENGES OF AHI APPLICATION}

Currently, in order to respond the increasingly demanding requirements in terms of asset management, the application of AHI models offer the possibility to improve the process of decision making in maintenance situations. After a review of the literature, the best practices agree that using the asset health index offers the following advantages:

- Consolidate all information sources about the asset condition in a single integrated view of asset health.

- Provide an approaching indication of the asset at the end of its useful life.

- Condition assessment and asset performance.

- Report generation for maintenance attention.

- Needs identification at short and medium term for the replacement of individual equipment.

- Prediction of long-term needs replacement in large volumes of assets, identifying potential peaks with investment requirements.

- Identify problems, risks and opportunities for maintenance management.

- Provide information on asset deterioration trends that do not correspond to the rates of natural aging processes, which can be useful for planning appropriate maintenance strategies.
- Comparison between the assets condition by classes and locations, allowing taking actions in the operation and maintenance strategy of the organization.

On the other hand, any organization that decides to implement this tool in their strategic processes, with the purpose to improve its asset management, will have to take into account the below-mentioned considerations. Depending on the level of maturity of the organization, in some cases, they may be a challenge to overcome and, in others, an inconvenience to avoid or mitigate:

- The collection of data has a high cost. The capture of certain information requires a field technician in order to inspect and record the data.

- Uncertainty in evaluating asset conditions can create inconsistencies in the collection of data.

- Uncertainty about the return on investment, the valuation of costs and the financing of assets replacement or renewal, can make difficult to determine the information

- The lack of consistent and compatible methods to record, store and reference information can cause errors in the analytical phase.

Once these advantages and disadvantages have been seen, it's worth investigating the implementation of the AHI tool. The initial part of capture and processing of the data is critical; improving in this initial stage the assets management will ensure better results. For any organisation that decides to apply the AHI tools, its essential to incorporate in its asset management model, the condition study of the asset after replacement promoted by a decision based on the asset health. This will allow the learning and adjustment of the mathematical model based on their own experience, which will be benefited in better results in making long-term decisions.

\section{CONCLUSIONS}

Today, the use of tools for decision making about long-term renewal and replacement of equipment for organizations is quite extended. Thanks to Life-Cycle Cost analysis (LCC), it is possible to know from an economic point of view, the cost of an asset over its useful life and to estimate the time for replacement if needed. The disadvantage in many cases, is the large amount of variables that must be handled when estimating the real cost of an asset over its useful life, generating a scenario of high uncertainty (Durairaj et al. 2002). At that moment, it is where the AHI comes into play as a support tool, having a completely different calculation methodology, estimated from lab tests in order to know the asset condition, visual inspections, 
operation and maintenance history and the age of the equipment and its components.

The roadmap for the definition of an AHI model is applicable to different kinds of equipment. It is currently under development and such development is generating the need to open new lines of research, in parallel to what is currently implemented in the field of electrical networks and more specifically in electrical transformers.

\section{REFERENCES}

Abichou, B., A. Voisin, and B. Iung. 2015. "Choquet Integral Capacity Calculus for Health Index Estimation of Multi-Level Industrial Systems." IMA Journal of Management Mathematics 26(2):205-24. Retrieved February 7, 2018 (https://academic.oup.com/imaman/ article-abstract/doi/10.1093/imaman/dpu006/644089/ Choquet-integral-capacity-calculus-for-health).

Abichou, B., A. Voisin, B. Iung, P. Do Van, and N. Kosayyer. 2012. "Choquet Integral Capacities-Based Data Fusion for System Health Monitoring." IFAC Proceedings Volumes 45(20):31-36. Retrieved February 7, 2018 (https://www.sciencedirect.com/science/ article/pii/S1474667016347279).

Azmi, A., J. Jasni, N. Azis, and M.Z. A.Ab. Kadir. 2017. "Evolution of Transformer Health Index in the Form of Mathematical Equation." Renewable and Sustainable Energy Reviews 76(March):687-700. Retrieved (http://linkinghub.elsevier.com/retrieve/pii/ S1364032117304306).

Durairaj, Senthil Kumaran, S.K. Ong, A.Y.C. Nee, and R.B.H. Tan. 2002. "Evaluation of Life Cycle Cost Analysis Methodologies." Corporate Environmental Strategy 9(1):30-39. Retrieved December 5, 2017 (https://www.sciencedirect.com/science/article/pii/ S1066793801001415).
Hjartarson, Thor and Shawn Otal. 2006. "Predicting Future Asset Condition Based on Current Health Index and Maintenance Level." in ESMO 2006-2006 IEEE 11th International Conference on Transmission \& Distribution Construction, Operation and Live-Line Maintenance.

Ludovic Rizzolo, Bouthaina Abichou, Alexandre Voisin, Naïm Kosayyer. 2011. "Aggregation of Health Assessment Indicators of Industrial Systems." in The 7th conference of the European Society for Fuzzy Logic and Technology, EUSFLAT-2011. Retrieved February 7, 2018 (https://hal.archives-ouvertes.fr/ hal-00605121/).

Naderian, A., S. Cress, R. Piercy, F. Wang, and J. Service. 2008. "An Approach to Determine the Health Index of Power Transformers." Conference Record of the 2008 IEEE International Symposium on Electrical Insulation (July 2008):192-96. Retrieved (http://ieeexplore.ieee.org/lpdocs/epic03/wrapper. htm?arnumber=4570308).

Naderian, A., R. Piercy, S. Cress, J. Service, and W. Fan. 2009. "An Approach to Power Transformer Asset Management Using Health Index." IEEE Electrical Insulation Magazine Vol. 25(No. 2):2.

Pompili, M. and F. Scatiggio. 2015. "Classification in Iso-Attention Classes of Hv Transformer Fleets." IEEE Transactions on Dielectrics and Electrical Insulation 22(5):2676-83.

Scatiggio, F., M. Rebolini, Terna Rete Italia, and M. Pompili. 2016. "Health Index: The Last Frontier of TSO's Asset Management." 1-9.

Scatiggio, Fabio and Massimo Pompili. 2013. "Health Index : The TERNA's Practical Approach for Transformers Fleet Management." (June):178-82.

Vermeer, M., J. Wetzer, P. van der Wielen, E. de Haan, and E. de Meulemeester. 2015. "Asset-Management Decision-Support Modeling, Using a Health and Risk Model." PowerTech, 2015 IEEE Eindhoven 1-6. 